\title{
The effects of stimulation of the amygdala on food and water intake in rabbits
}

\author{
KLAUS SCHNEIDER and DONALD NOVIN \\ Department of Psychology and Brain Research Institute, \\ University of California, Los Angeles, California 90024
}

\begin{abstract}
The amygdala is supposed to have a dual modulatory influence on instigating and inhibiting central functions of alimentary behavior. Electrical stimulation of the basolateral amygdala in rabbits suppressed food and water intake during stimulation but had no aftereffects. Stimulation of the corticomedial amygdala had no discernible effects on food and water intake.
\end{abstract}

The role of the amygdala complex in alimentary behavior has been reviewed recently by Fonberg (1974). The results of lesioning and stimulation studies are quite different across species and with slightly different lesions or stimulation placements. If one considers the functional division of the amygdala complex, as proposed by several investigators (Fonberg, 1968; Kaada, 1972; Koikegami, 1963), between a phylogenetic and ontogenetic older corticomedial or dorsomedial complex (CMA) and a new basolateral part (LA), the divergent results appear to fit a simple scheme. According to Fonberg (1974) and Kaada (1972), these two amygdaloid systems duplicate the much more investigated hypothalamic systems of food and water intake. The CMA has an instigating, the LA-complex an inhibiting, effect on alimentary behavior (Fonberg, 1963), probably by modulating the hypothalamic systems (Gloor, 1955).

It has been shown that stinulation of the LA inhibits feeding in cats (Fonberg \& Delgado, 1961; Lewinska, 1968), rats (Morgane, 1962), and dogs (Fonberg, 1963), whereas stimulation of the CMA enhanced food intake in cats (Levinska, 1968). These results have been supported by the results of lesion studies. Lesions in the CMA produced a short aphagia and a longer lasting hypophagia in dogs, whereas lesions in the LA produce a hyperphagia in the same species (Fonberg, 1969, 1971; Fonberg \& Sychowa, 1968). Recently, Box and Mogenson (1975) reported similar findings in rats, yet they did not find the marked similarities beteen the hypothalamic syndromes and amygdala lesion syndromes that Fonberg (1974) had reported in dogs.

A preliminary study of the importance of the amygdala complex for food intake behavior in rabbits in our laboratory has shown (cf. Fonberg, Schneider,

This research was supported by Grant NS7687 from NINCDS to D. N. K. S. is now at Ruhr-University, Bochum, German Federal Republic.
\& Novin, 1975) that lesions in the CMA produced only a very short period of aphagia and hypophagia, but may have impaired other important mechanisms of food-intake control. In order to explore the significance of the amygdaloid complex in this species further, it seemed worthwhile to assess the effects of stimulating different parts of the rabbit amygdala.

\section{METHOD}

\section{Subjects}

The subjects were nine female albino rabbits with a mean weight of $3.77 \pm 0.70 \mathrm{~kg}$ at the start of the experiment. Two animals were run in a pilot, seven in the main study. The animals were maintained in individual cages with free access to food and water, except as stated in the procedure section. The room was air conditioned, with temperature maintained between $17^{\circ}$ and $20^{\circ} \mathrm{C}$. Lights went on at 0700 and off at $1900 \mathrm{~h}$.

\begin{abstract}
Apparatus
A Trent Wells stereotaxic instrument was use: to implant the stimulating electrodes. The bipolar electrodes :vere made from twisted stainless steel wire $(0.1-\mathrm{mm}$ diam) insulated with Teflon except for the cut edges. Tips were $0.5 \mathrm{~mm}$ apart. The upper ends of the electrodes were squeezed into Amphenol miniature connectors, which were soldered to a Winchester miniature receptacle. The receptacle had a lock spring which allowed a firm connection with a suitable plug. The electrical connection from this plug to a selector panel on the roof of the testing chamber was established with a nine-strand low-noise Microdot cable, suspended elastically from the roof of the room.

Stimulation was given bilaterally with an S 88 Grass stimulator connected to two stimulus isolation units (SIU 5). The current delivered to the animal was controlled separately for the two channels and monitored on a dual-beam Tectronix oscilloscope (Type 502 A).

The EEG was recorded with a Grass $5 \mathrm{D}$ polygraph in bipolar fashion from the electrodes not being used for stimulation. Behavioral testing was carried out in a canine flight cage, which had an aperture on top of the roof in order to allow the free movement of the electrical cable. Food was offered in a dish in the cage, water in a $100-\mathrm{ml}$ graded tube clipped to the wire front door of the cage.
\end{abstract}

\section{Surgery and Histological Procedure}

All animals were operated on under Nembutal anesthesia $(30 \mathrm{mg} / \mathrm{kg})$, using aseptic methods. The animal was placed into the stereotaxic instrument, the skull was exposed, and four holes 
drilled through it. The electrodes were lowered to the lateral amygdala (LA) and the corticomedial amygdala (CMA). All animals had four electrodes, two in LA and two in CMA. Coordinates were taken from an atlas of the rabbit brain (Urban \& Richard, 1972). (1) LA: $7.00 \mathrm{~mm}$ lateral; $.5-1.0 \mathrm{~mm}$ posterior (from bregma); 16.5-17.0 deep (from skull surface). (2) CMA: $4.0 \mathrm{~mm}$ lateral; 2.5 (Nos. 1 and 2), $1.5-1.0 \mathrm{~mm}$ anterior (from bregma); 16.5-17.5 deep. At the end of the experiment, lesions were made at the tip of the electrodes by passing $10 \mu \mathrm{A}$ dc anodal current for $10 \mathrm{sec}$. The animals were then perfused under Nembutal anesthesia via a carotid artery with physiological saline, followed by $10 \%$ Formalin solution with $10 \mathrm{gm} / 100 \mathrm{ml}$ ferrocyanide diluted in the saline. Frozen sections were cut at $80 \mu$ and stained with carbolfuchsin. Ferrocyanide spots could be identified and the tracks of the electrodes reconstructed.

\section{Behavioral Testing and Stimulation}

Animals were first adapted to a food-deprivation schedule. Food was removed from their home cages at $1800 \mathrm{~h}$. They were then given access to food for $10 \mathrm{~min} 17 \mathrm{~h}$ later in the testing chamber and later in their home cage for an additional $61 / 2 \mathrm{~h}$. The 20-min testing time was divided in two 10 -min periods. The animals were given a full dish of food at the beginning of every 10-min period, the amounts eaten were measured to the nearest $0.1 \mathrm{~g}$. When the amount eaten in the first 10 -min period remained stable for 3 consecutive days $( \pm 10 \%)$, the experiment proper began. The same procedure was followed in adapting the animals to a water-deprivation schedule. Here, water was removed at $1800 \mathrm{~h}$ and animals were given free access to water for $20 \mathrm{~min}$ $20 \mathrm{~h}$ later in the testing chamber and for an additional $31 / 2 \mathrm{~h}$ in their home cage. Drinking tests always followed the series of eating tests.

Electrodes in the lateral amygdala were tested separately for suppression of food intake. Rectangular pulses of 0.5 -msec duration were delivered in trains of $0.1-\mathrm{sec}$ duration at a constant frequency of $50 \mathrm{~Hz}$. The stimulation current and the train frequencies were varied in order to keep the animals from eating. This was possible with different animals at stimulation currents between .005 and $.4 \mathrm{~mA}$ and at train frequencies between 1 and $3 / \mathrm{sec}$. In pilot work, no discernible effects of CMA stimulation were seen when a wide range of stimulus parameters was used. For this reason, we used the same parameters for CMA stimulation that were found effective when stimulating LA. The current necessary to produce the various skeletal motor and facial muscle effects (Kaada, 1972) with the same parameters was generally three times higher than the threshold current inhibiting eating. All animals were tested at the end of the experiment with increasing currents for seizure effects. Spike discharges also could only be recorded at currents three times higher than those with behavioral effects. Animals used for pilot experiments were not used in the main experiment, nor is their data included in these results.

Stimulation was delivered bilaterally only in the first 10-min period (period I). The animals started either with stimulation of the LA or with stimulation of the CMA, in alternating order. LA stimulation was always followed by an adjusted test day, in which the animals received in period I (first $10 \mathrm{~min}$ ) only as much food or water as they had consumed in period I with stimulation of the LA (cf. White \& Fisher, 1969). This day was followed by a neutral control day, as was the day of stimulation of the CMA. Testing was done every day, with one replication for every treatment. Means of food and water intake were computed first for every animal over the two measurements in every treatment; the means of the 2 control days which followed both the adjusted testing and the CMA stimulation were averaged, as there were no differences between those 2 control days. The group means of food and water intake were then compared by $t$ tests for dependent measurements $(\mathrm{df}=6)$.

\section{RESULTS}

\section{Histological Verification}

All animals in the study completed the entire procedure. The histology of the brains showed that the tips of the electrode aimed to the LA were at least unilaterally in or very near the LA complex, mostly in the anterior part of the LA proper or in the magnocellular part of the basal amygdala. The electrodes aimed at the CMA complex were in the first three animals too anterior-either in the anterior amygdala or in the pyriform cortex. The last four animals had at least one electrode in or near the CMA.

Figure 1 shows the placements of the electrode tips in the LA complex and for the last four animals, in the CMA complex.

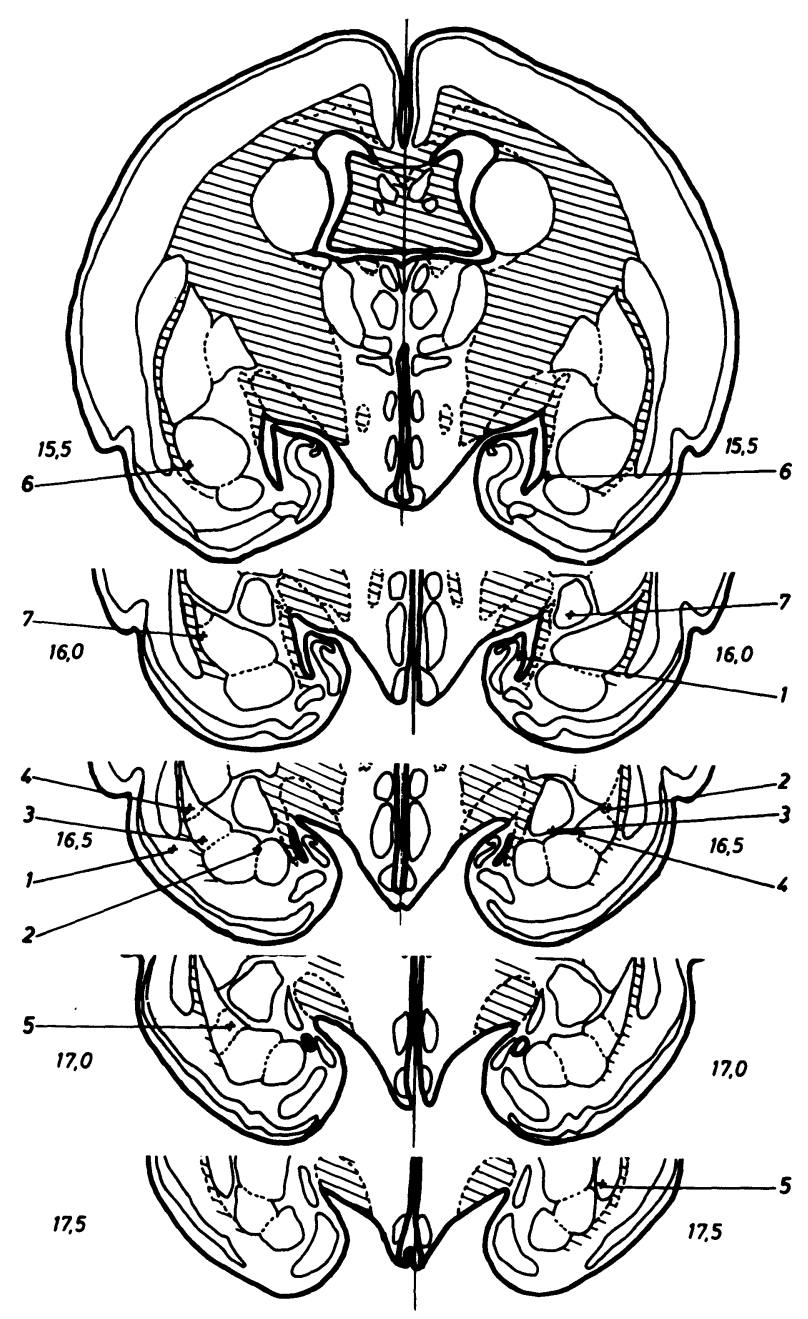

Figure 1a. Reconstruction of the stimulation sites in the LA (4 animals only). The figure is drawn from an atlas of the rabbit brain (Urban \& Richard, 1972). 


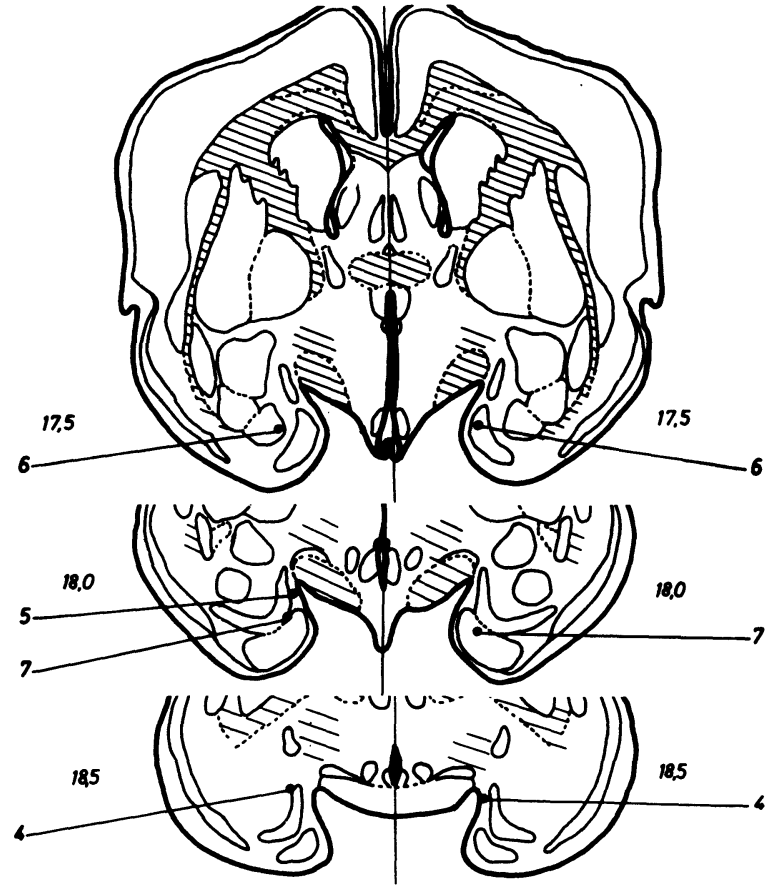

Figure 1b. Reconstruction of the stimulation sites in the CMA (4 animals only). The figure is drawn from an atlas of the rabbit brain (Urban \& Richard, 1972).

\section{Effects of Stimulation}

Figure 2 shows the results of stimulation of the LA and CMA on food and water intake. The means and standard errors (S.E.M.) are computed from the average amount eaten and drunk by each animal in the 2 testing days for every treatment. Only the results for those four animals which had at least one electrode in the CMA complex are shown for the CMA stimulation condition; in the other conditions, the results of all seven animals are shown.

Stimulation of the LA in period I clearly suppresses food and water intake compared with the control condition ( $p<.001$ and $p<.05$, respectively).

On average, when stimulated in the LA, the animals ate $77 \%$ less food and drank $81 \%$ less water than on control days. Stimulation of the LA did not have any aftereffects: In period II, after stimulation of the LA, the animals did not eat or drink less than on adjusted test days. In both cases, they compensated for the reduced food and water intake in period I and, in period II of the stimulation and adjusted test days, ate 4 to 5 times more than on control days and drank 6 to 7 times more. All effects are statistically significant ( $\mathrm{p}<.025$ and smaller).

All individual animals did show the suppression of food intake during LA stimulation. One animal (No. 2), however, did not show the suppression effect in respect to water intake, and one other animal (No. 6) stopped drinking altogether in the testing chamber after the second day.
Besides the immediate effects of the LA stimulation, there were no differences in the amount eaten in the $6.5 \mathrm{~h}$ in which the animals had free access to food in their home cages or in the amount they drank in the $3.5 \mathrm{~h}$ of free access to water in the second part of the experiment. Food-deprived animals ate, on average, $84.1 \pm 26.6 \mathrm{~g}$ after stimulation of the LA and $87.9 \pm 18.6 \mathrm{~g}$ on control days. Water-deprived animals drank $175 \pm 65 \mathrm{ml}$ after LA stimulation and $174 \pm 39 \mathrm{ml}$ on control days.

Stimulation of the CMA complex on those four animals where at least one electrode was in the CMA (cf. Figure 1) did not enhance food intake as predicted; instead, compared with the control condition,
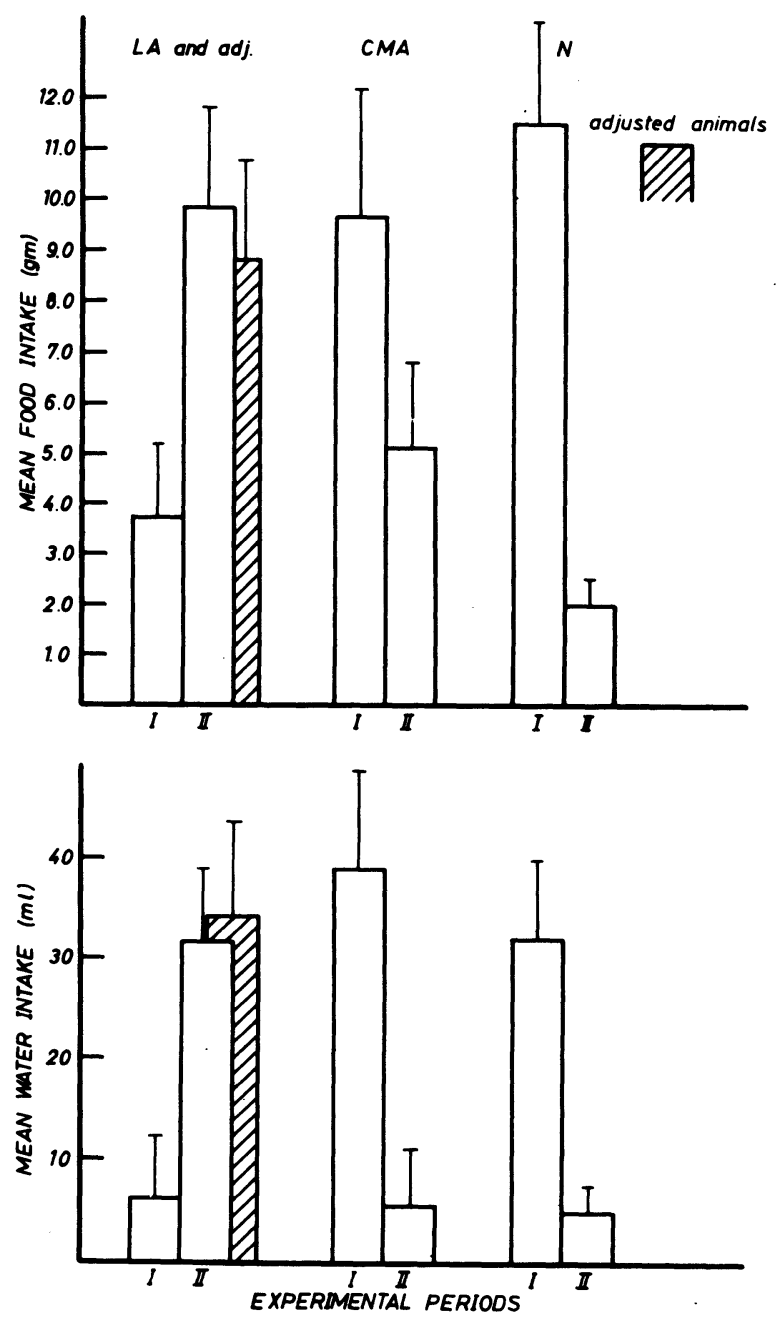

Figure 2. Food and water intake during (period I) and after (period II) stimulation of the lateral amygdala (LA) and the corticomedial amygdala (CMA), in an adjusted (adj.) experimental condition and in a neutral condition (N). In the last two conditions, there was no brain stimulation: The animals had free access to food or water in both periods in the control condition and received as much food or water in period I of the adjusted condition as they had taken during LA stimulation. In the CMA condition, only the amounts consumed by those four animals with electrode placements in the CMA complex are shown. 
it suppressed it slightly by $24 \%$ (n.s.). However, water intake during CMA stimulation was up $20 \%$ (n.s.) compared with the control condition. There was no overlap in the amounts eaten and drunk during CMA stimulation compared with LA stimulation. Amounts of food $(90.3 \pm 13.6 \mathrm{~g})$ and water $(192.5$ $\pm 58.3 \mathrm{ml}$ ) taken in the 6.5 and $3.5 \mathrm{~h}$, respectively, of free access in the home cage after CMA stimulation were comparable to the amounts eaten and drunk on neutral days and after stimulation of LA. The three animals with electrode tips in the anterior amygdala or cortex ate and drank equivalent amounts during stimulation $(8.5 \mathrm{~g}$ and $41 \mathrm{ml})$ as these four animals.

The animals were apparently not disturbed by the CMA stimulation or stimulation of the anterior amygdala, but showed signs of an "alert" reaction with stimulation of the LA. In all animals but one, the pupils were dilated during stimulation of the LA; but animals were not inhibited in all behavior. During LA stimulation, some animals started cleaning their fur. All animals spent some time exploring the test chamber and some time scratching the walls. Five of seven animals came very near the food dish or the water bottle without eating or drinking.

\section{DISCUSSION}

The results show that low-intensity stimulation of the basolateral amygdaloid complex inhibits food and water intake in rabbits. The stimulation produces no aftereffects, a finding which is at variance with the longer lasting effects which have been found in cats by Fonberg and Delgado (1961) and Lewinska (1968). Although not all ongoing behavior was inhibited, the effect is apparently not specific, as food and water intake were inhibited alike, possibly by an "alert" or "attention" reaction which was observed in all our animals with this kind of stimulation. Such an alert reaction has been shown in a number of studies with cats (cf. Kaada, 1972; Ursin \& Kaada, 1960). Stimulation of the CMA under the conditions of this experiment did not enhance food and water intake. As the animals were food or water deprived, this might be a ceiling effect, yet observations of the feeding behavior in the pilot studies with nondeprived animals did not demonstrate any enhancement of food intake either.

However, as food and water intake was not suppressed by the CMA stimulation, at least the assumption of a functional division of the amygdala is supported for the rabbit's brain too. Neuroanatomists have described differences in the structure and the connections of the amygdaloid nuclei between various species of mammals (Ban \& Omukai, 1959; Hall, 1972; Lammers, 1972); further experimentation is thus needed to clarify the significance of the amygdala for alimentary behavior in the rabbit.

\section{REFERENCES}

Ban, T., \& Omukai, F. Experimental studies on the fiber connections of the amygdaloid nuclei in the rabbit. Journal of Comparative Neurology, 1959, 113, 245-279.

Box, B. M., \& Mogenson, G. J. Alterations in ingestive behavior after bilateral lesions of the amygdala in the rat. Physiology and Behavior, 1975, 15, 679-688.

FoNBERG, E. The inhibitory role of amygdala stimulation. Acta Biologica Experimentalis, 1963, 23, 171-180.

FonBERG, E. The role of the amygdaloid nucleus in animal behavior. Progress in Brain Research, 1968, 22, 273-281.

FoNBERG. E. Effect of small dorsomedial amygdalar lesions on food intake and acquisition of instrumental alimentary reactions in dogs. Physiology and Behavior, 1969, 4, 739-743.

FoNGERG, E. Hyperphagia produced by lateral amygdalar lesions in dogs. Acta Neurobiologica Experimentalis, 1971, 31, 19-32.

FonBERG, E. Amygdala functions within the alimentary system. Acta Neurobiologica Experimentalis, 1974, 34, 435-466.

Fonberg, E., \& Delgado, J. M. R. Avoidance and alimentary reactions during amygdala stimulation. Journal of Neurophysiology, 1961, 24, 651-664.

FonberG, E., \& Sychowa, B. Effects of partial lesions of the amygdala in dogs. I. Aphagia. Acta Biologica Experimentalis, 1968, 28, 35-46.

Fonberg, E., Schneider, K., \& Novin, D. Deficits in the control of feeding following amygdala lesions in the rabbit. Federation Proceedings, 1975, 34, 373. (Abstract)

GLOoR, P. Electrophysiological studies on the connections of the amygdaloid nucleus in the cat. II. The electrophysiological properties of the amygdaloid projection system. Electroencephalography and Clinical Neurophysiology, 1955, 7, 243-264.

HaLl. E. Some aspects of the structural organization of the amygdala. In B. E. Eleftheriou (Ed.), The neurobiology of the amygdala. New York: Plenum Press, 1972. Pp. 95-121.

KAADA, B. R. Stimulation and regional ablation of the amygdaloid complex with reference to functional representations. In B. E. Eleftheriou (Ed.), The neurobiology of the amygdala. New York: Plenum Press, 1972. Pp. 319-342.

KoIkegami, H. Amygdala and other related limbic structures. Experimental studies on the anatomy and function. I. Anatomical researches with some neurophysiological observations. Acta Medica et Biologica, 1963, 10, 161-277.

LAMMERS, H. J. The neural connections of the amygdaloid complex in mammals. In B. E. Eleftheriou (Ed.), The neurobiology of the amygdala. New York: Plenum Press, 1972. Pp. 123-144.

LEWINSKA, M. K. Inhibition and facilitation of alimentary behavior elicited by stimulation of amygdala in the cat. Acta Biologica Experimentalis, 1968, 28, 23-24.

Morgane, P. J. Amygdala stimulation effects on instrumental alimentary and avoidance reactions in rats. Proceedings XII International Physiology Congress (Leiden), 1962, No. 363.

Morgane, P. J., \& Kosman, A. J. A rhinencephalic feeding center in the cat. American Journal of Physiology, 1959, 197, 158-162.

URBAN, J., \& RICHARD, P. H. A stereotaxic atlas of the New Zealand rabbit's brain. Springfield, Ill: Thomas, 1972.

Ursin, H., \& KAADA, B. R. Functional localization within the amygdala complex in the cat. Electroencephalography and Clinical Neurophysiology, 1960, 12, 1-20.

White, N. M., \& Fisher, A. E. Relationship between amygdala and hypothalamus in the control of eating behavior. Physiology and Behavior, 1969, 4, 199-205. 